\title{
Cavopulmonary assist: Bridge to Fontan repair of single-ventricle circulation
}

\author{
Mark Rodefeld, MD
}

\footnotetext{
From the James Whitcomb Riley Hospital for Children, Indiana University School of Medicine, Indianapolis, Ind. M.D.R. has been funded by NIH R21 HL080089 Exploratory/Developmental Bioengineering Research Grant, Bridge to neonatal Fontan repair of single ventricle; NIH R01 HL098353 Cavopulmonary assist: circulatory support for Fontan circulation.

Disclosures: Author has nothing to disclose with regard to commercial support.

Received for publication Sept 22, 2016; accepted for publication Sept 23, 2016; available ahead of print Nov 17 , 2016.

Address for reprints: Mark Rodefeld, MD, Indiana University School of Medicine, Emerson Hall 215, 545 Barnhill Dr, Indianapolis, IN 46202 (E-mail: rodefeld@iupui.edu).

J Thorac Cardiovasc Surg 2017;153:448-9

$0022-5223 / \$ 36.00$

Copyright (c) 2016 by The American Association for Thoracic Surgery

http://dx.doi.org/10.1016/j.jtcvs.2016.09.075
}

The Toronto group is courageously tackling the intractable problem of neonatal single-ventricle palliation. Despite the clinical uptake of significant alternative procedures (right ventricle-pulmonary artery shunt, hybrid procedures), their impact has been incremental and outcomes remain a challenge. An entirely different approach may be necessary, providing the impetus behind the study of Honjo and colleagues ${ }^{1}$ in this issue of the Journal.

In healthy neonates with biventricular circulation, pulmonary vascular resistance (PVR) drops nearly to adult values within hours after birth. Hypoxemia is absent, and PVR remains low-as long as there is no reactive stimulus. The risk for reactivity diminishes during transitional pulmonary maturation (approximately 2-4 months). In neonates with single-ventricle circulation, a systemic-to-pulmonary arterial shunt is used as a high-pressure source of pulmonary blood flow, ostensibly to overcome elevated PVR. Under "optimal" physiologic conditions, however, PVR should theoretically be low.

Here lies the enigma of neonatal single-ventricle palliation. The shunt paradoxically induces and sustains the pathophysiology that mandates it. High-pressure flow and hypoxemia are potent stimuli of pulmonary hypertension. The parallel arrangement of the systemic and pulmonary circulations is inherently unstable. The hypoxia-stressed ventricle is volume overloaded. Pulmonary vascular maladaptation likely worsens eventual Fontan candidacy and long-term status. Not surprisingly, clinical courses are correspondingly difficult and, all too expectedly, unexpectedly end poorly. If the problematic shunt could be avoided, these problems could be resolved.

A series circulation is inherently stable, with normoxia and normal volume. Neonatal pulmonary perfusion from a systemic venous source (neonatal Glenn or Fontan circulation) will, however, require a modest pressure boost (about 6-12 $\mathrm{mm} \mathrm{Hg}$ ) from a subpulmonary power source for some period. This requirement led to

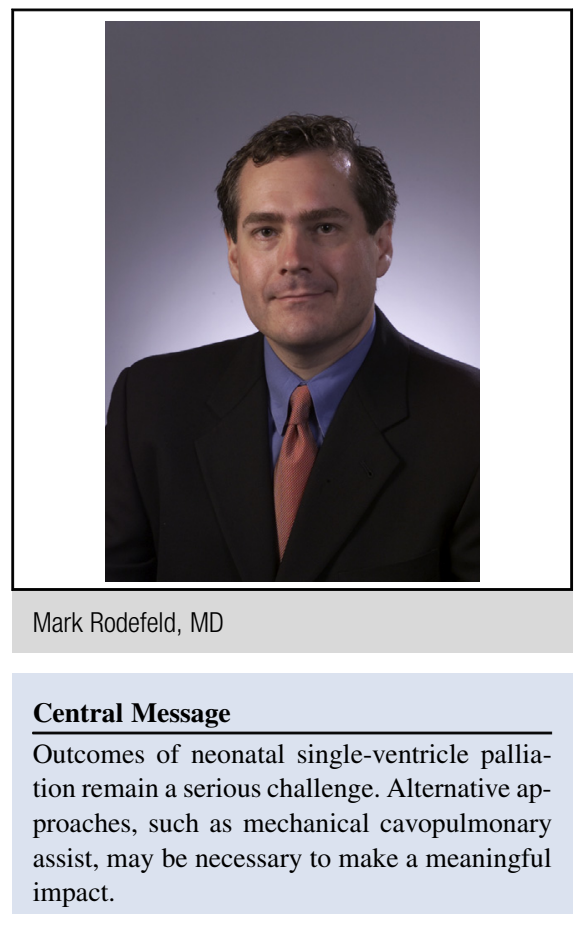

See Article page 441 . the concept of bridge support with mechanical cavopulmonary assist. ${ }^{2}$

To this end, the study of Honjo and colleagues ${ }^{1}$ provides acute physiologic insight into mechanically assisted bidirectional Glenn shunt (combined stages I and II) as initial palliation. A superior cavopulmonary shunt with mechanical assist is used in lieu of a systemic-to-pulmonary arterial shunt, producing a theoretically more stable "series" circulatory arrangement. It is only a "partial series" circulation, however; inferior vena caval flow continues into the systemic circulation, and hypoxemia persists. Although an assisted Glenn shunt may reduce instability risk, it may provide an incomplete solution.

A mechanically assisted Fontan circulation (combined stages I, II, and III) is theoretically a complete solution. ${ }^{3}$ The pulmonary and systemic circuits are fully separated, and hypoxemia and volume overload are eliminated. This may seem unrealistic, but it would emulate normal biventricular circulatory physiology (imagine a stable Norwood circulation with alveolar $\mathrm{Po}_{2}>400 \mathrm{~mm} \mathrm{Hg}$ ) and may yield the best long-term outcomes. Technology that can safely 
and reliably mechanically assist Glenn and Fontan flows is emerging, but it has yet to be clinically translated. ${ }^{4}$

Although cavopulmonary assist is an exceedingly complex technical challenge, it has the potential to provide meaningful advances in single-ventricle repair, including the possibility of correction rather than palliation. This study is an important step in that direction. Otherwise, we are condemned to keep repeating the past. Unconventional approaches are difficult; however, patients with singleventricle anatomy fare poorly in the current pathogenic paradigm and stand to benefit greatly from a paradigm shift.

\section{References}

1. Honjo O, Merklinger SL, Poe JB, Guerguerian AM, Zhang H, Taylor KL, et al. Mechanically assisted bidirectional cavopulmonary shunt in neonates and infants: an acute human pilot study (mechanically-assisted BCPS). J Thorac Cardiovasc Surg. 2017; 153:441-7.

2. Rodefeld MD, Frankel SH, Giridharan GA. Cavopulmonary assist: (em)powering the univentricular Fontan circulation. Semin Thorac Cardiovasc Surg Pediatr Card Surg Annu. 2011;14:45-54.

3. Rodefeld MD, Boyd JH, Myers CD, Presson RG Jr, Wagner WW Jr, Brown JW. Cavopulmonary assist in the neonate: an alternative strategy for single-ventricle palliation. J Thorac Cardiovasc Surg. 2004;127:705-11.

4. Rodefeld MD, Coats B, Fisher T, Giridharan GA, Chen J, Brown JW, et al. Cavopulmonary assist for the univentricular Fontan circulation: von Kármán viscous impeller pump. J Thorac Cardiovasc Surg. 2010;140:529-36. 